\title{
Pest management decision support systems: A new challenge for forest entomologists
}

\author{
by Larry D. Marshall ${ }^{1}$ and Deborah G. McCullough ${ }^{2}$
}

\section{Introduction}

Forestry is inarguably a complex business and is becoming more so with our growing concerns for other uses of the forest such as wildlife and recreation. Public awareness of natural resource issues requires that forest managers provide concrete and astute rationales for their decisions during public hearings. Such attributes of modern forestry, coupled with the existence of powerful computer hardware and software, have increased our emphasis on the development of decision support systems (DSS) to aid in data integration, decision-making, and the presentation of information.

These changes present opportunities for forest entomologists to participate in development of pest management DSS. A common lament of forest entomologists has been that, while their advice is frequently requested during pest outbreaks, they often have few opportunities to provide recommendations for long-term pest management. Participation in DSS development offers them the opportunity to get their knowledge of forest insect pests incorporated into the decision making process. Silvicultural recommendations and guidelines for long-term pest management can be integrated with other management objectives during the planning operations.

Much of this integration is made possible by the use of powerful computer technology in DSS, including geographic information systems (GIS). In addition, utilization of DSS and GIS technology can make scientific knowledge of forest pest management accessible, enhancing our ability to explain pest impacts, dynamics, or management recommendations to resource professionals and the general public. For example, GIS maps of relative stand hazard ratings were produced by the joint Canada-U.S. jack pine budworm DSS project for the Hiawatha National Forest in Michigan (McCullough and Marshall 1992). These maps were used by district silviculturalists to prioritize stands for harvest and to justify their decisions during meetings with local environmentalists. Currently, entomologists in Canada and the U.S. are involved in several projects to develop DSS for pests such as hemlock looper, spruce budworm, jack pine budworm, southern pine beetle, gypsy moth, and mountain pine beetle.

Two significant challenges face forest entomology researchers who choose to participate in the construction of DSS. First, entomologists must understand what DSS are and how directing efforts towards DSS production rather than publications should affect their own decision-making processes and the nature of the questions they attempt to answer. Secondly, because DSS are deliverable products that will be used within a forest management environment, forest entomologists need to be more aware of differences between this environment and the scientific one with

\footnotetext{
${ }^{1}$ Pest Management Systems, Petawawa National Forestry Institute, Chalk River, Ontario, Canada K0J $1 \mathrm{~J} 0$.

${ }^{2}$ Department of Entomology and Forestry, 243 Natural Science Building, Michigan State University, East Lansing, MI, USA 48824.
}

respect to constraints and priorities and how these affect the way they approach decision support system development.

\section{What is a Pest Management DSS?}

A decision support system is not a research model, of which many have been produced by the entomological community in the past. Research models are developed by scientists, for scientists, generally with research-oriented goals in mind. The delivered products in this case are self-contained publications, not software. DSS, however, are software systems which serve as tools for the forest manager and must address questions important to forest managers, not scientists. They must also provide those answers in a context that is relevant to the forest manager; that is, within the context of time and money constraints.

Decision support itself can be divided into two categories: assistance in making a decision and support of decisions when presenting them to other people. Forest managers are, more and more, realizing a need for the latter, whereas scientists may concentrate almost exclusively on the predictive power of DSS. Involving forest managers more completely in product design will facilitate the realization of more useful systems.

To shift the deliverable product from publication to operational software products requires that scientists must be responsive to the demands and views of forest managers in much the same way as they are responsive to the peer review system when their product goals are publications. It is important to recognize the gravity of this statement. The scientific peer review and reward system cannot help but affect a scientist's view of what is worthy of study (i.e. is it publishable?). It also affects the view of how good the data and results must be before they are useful (i.e. publishable conclusions generally require $95 \%$ confidence that the conclusions are valid). These two factors, in turn, determine whether the question before the scientist is "tractable" and, if so, how the problem should be approached. Scientists participating in DSS development must realize that the perspectives and needs of forest managers almost invariably will replace the more traditional academic publication criteria in determining where efforts will be focused and how problems will be approached.

\section{Perspectives of the Forest Manager and Research Entomologist}

While scientists often have the luxury of selecting their questions based upon what data are available, forest managers are not able to select the questions they need to answer. The questions they face are determined by the management context. This point may seem trite, but it reflects the most important distinction between traditional science and decision support system development. Questions addressed by DSS are those that forest managers must answer with or without the help of the scientific community. Thus, DSS attempt to improve the manager's current situation, not necessarily provide an answer that would pass the scrutiny of the scientific community. 
Most population dynamics research on forest defoliators has been done on large geographical and temporal scales (Campbell 1993; Campbell and Sloan 1977, 1978; Ives 1981; Meyers 1993; Royama 1984; Volney 1988). This reflects the availability of data for traditional time series approaches to problems and a heavy emphasis on long term population dynamics. Forest managers, however, are typically more concerned with short temporal and small geographical scales (e.g. annual treatment scheduling, stand level impacts).

Many entomologists have generally been interested in predicting the mean population size, rates of population change, and in gaining an understanding of the nature of processes controlling population size. In contrast, forest managers tend to have more of a relative view of pest-related phenomena (e.g. Which stands will be affected the most?) among stands within the forest as this type of information is needed to prioritize silvicultural activities, including harvest or salvage of forests. While it is true that if the entomologist is successful, both absolute and relative risk can be derived, this approach may require far more understanding and data than is available. Thus the goal, absolute (scientific) or relative (forestry) risk assessment, affects how questions should be approached and determines if they can be answered at all with current knowledge and resources. Entomologists in DSS projects must be sensitive to this difference and willing to forsake the more general quest for basic knowledge if it means providing solutions to the immediate problems of forest managers. At the same time, DSS development provides ample opportunity for forest entomologists to identify the most relevant knowledge and data gaps which they can pursue in more traditional ways.

Due to resource constraints, researchers, including entomologists, have generally worked on well defined problems (e.g. What is the nature of an insect's population cycle?; What is the nature of spread of a population?; What stand parameters affect vulnerability to the insect?). Forest managers have to deal with these same questions but simultaneously (e.g. What is the predicted distribution of insect damage in my forest next year?). Therefore, entomologists must integrate consideration of several discrete questions in the development of a DSS if they are to provide managers with useful tool, a demand that exceeds the capacity of most scientific models.

\section{Knowledge Assembly vs. Knowledge Creation}

To deliver a DSS, decisions must be made and considerable effort expended to provide something quite beyond a set of models. The process of constructing a functional decision support system is principally one of knowledge assembly, not knowledge creation, though the latter may also be part of the process. Scientists involving themselves, and those seeking their involvement, in a decision support system project should understand that many of the skills required in the development of such systems are quite varied. This means that DSS development must become a group activity and emphasis, by necessity, is placed upon the ability to communicate expertise using non-specialized language to group members from other domains.

\section{Data Availability}

When selecting a tractable question, data availability inevitably affects a researcher's decision-making process. But scientists rarely consider that the ability to predict can be limited by data and generally assume that knowledge is the limiting factor in making predictions. It is also important to note that the term "tractable question" has within it an understanding that it is a question that can be answered using methodologies and precision criteria suitable to peer review journals. Forest managers, in contrast, due to the fact that they have few resources to invest in sampling pest populations or on those factors that regulate pests, regularly face the reality that their ability to predict is limited by a lack of data.

This leads to scientists building models to the limits of their knowledge, assuming data will be available to drive such models. Forest managers often lose interest in such models because they cannot economically collect the required data. Even more unfortunate is the fact that if the precision requirements set by the researcher on the word "predict" were moderated somewhat, some of those models could be quite useful within an operating forestry environment. One solution to this problem is to broaden the view and ask not only what we need to know, but also what we can possibly predict from data available in an operational context. Severe limits are imposed on the pest modelling rigour and precision by these constraints as few pest-related data exist in a typical operational environment.

Because the goal of DSS is to support decisions, developers of such systems need to be less constrained by causeeffect modelling approaches. Because complete datasets are rarely available, we need to investigate the use of expert systems and/or neural network technology. To fill the voids in the best possible manner, these technologies are better able to draw inference from partial datasets than traditional modelling appraoches. Encapsulation of forest manager decision-making processes, including "best guess" estimates, into software can still provide considerable information by graphically displaying the results of such decision making processes. More emphasis should also be placed upon spatial analyses because forestry places a heavy emphasis on spatial prediction.

Paramount to the success of DSS projects is the need to involve forest managers themselves in determining the nature of the product. In our experience, participation in a DSS development project can enhance communication between scientists and managers, providing advantages to both groups.

\section{Acknowledgements}

The authors gratefully acknowledge valuable comments by Drs. S. Magnussen and M. Strome on an earlier version of the manuscript. We also thank A. Yapa for his editorial comments.

\section{References}

Campbell, R.W. 1993. Populations dynamics of the major North American needle-eating budworms. USDA For. Serv. Pap. PNW-RP463. 222 p.

Campbell, R.W. and R.J. Sloan. 1977. Forest stand responses to defoliation by the gypsy moth. For. Sci. Monogr. 19.

Campbell, R.W. and R.J. Sloan. 1978. Numerical biomodality among North American gypsy moth populations. Environ. Entomol. 7: 641-646.

Ives, W.G.H. 1981. Environmental factors affecting 21 forest insect defoliators in Manitoba and Saskatchewan, 1945-69. Info. Rep. NOE-X-233. Northern Forest Res. Centre, Canadian Forestry Service, Edmonton, Alberta.

Myers, J. 1993. Population Outbreaks in Forest Lepidoptera. 
American Scientist 81: 240-250.

McCullough, D. and L. Marshall 1992. Jack Pine Budworm Decision Support System: A Case Study. Compiler 11: 14-20.

Royama, T. 1984. Population dynamics of spruce budworm, Choristoneura fumiferana (Clem.): a reinterpretation of life table stud- ies from the Green River project. Ecol. Monogr. 54: 429-462.

Volney, W.J.A. 1988. Analysis of historic Jack pine budworm outbreaks in the prairie provinces of Canada. Can. J. For. Res. 18: $1152-1158$ 